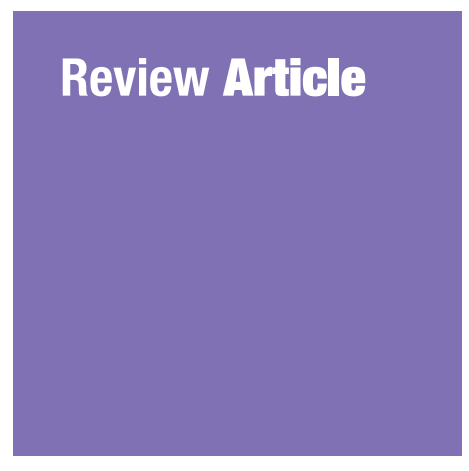

Submitted: 2 Jan 2019

Accepted: 21 Apr 2019

Online: 4 Nov 2019

\section{Interventions in Reducing Caesarean Section in the World: A Systematic Review}

\author{
Farideh Moradi ${ }^{1,2}$, Aidin Aryankhesal ${ }^{2}$, Mohammad HeIDari ${ }^{3}$, Ali \\ SOROUSH ${ }^{1}$, Sara RAHIMI SADR ${ }^{1}$ \\ 1 Life Style Modification Research Center, Imam Reza Hospital, Kermanshah \\ University of Medical Sciences, Kermanshah, Iran \\ Department of Health Services Management, School of Health Management \\ and Information Sciences, Iran University of Medical Sciences, Tehran, Iran \\ 3 Community-Oriented Nursing Midwifery Research Center, Shahrekord \\ University of Medical Sciences, Shahrekord, Iran
}

To cite this article: Moradi F, Aryankhesal A, Heidari M, Soroush A, Rahimi Sadr S. Interventions in reducing caesarean section in the world: a systematic review. Malays J Med Sci. 2019;26(5):21-37. https://doi.org/10.21315/ mjms2019.26.5.3

To link to this article: https://doi.org/10.21315/mjms2019.26.5.3

\begin{abstract}
Caesarean section without medical indication imposes many problems to families, personnel and medical equipment causing some side effects to pregnant woman and foetus, compared to natural childbirth. The present study aimed to evaluate the interventions in reducing caesarean section in the world. This study was a systematic review using Embase, PubMed, Scopus, Web of Science, Science Direct, Magiran and SID databases and grey literature. All studies conducted during 2000-2018 were reviewed and finally the studies with inclusion and exclusion criteria were selected. A total of 19 studies were selected among 5,559 studies. The interventions conducted for reducing caesarean section included training the specialists and women by using Six Sigma method, changing the guidelines, reviewing the definition of natural childbirth various stages, encouraging the natural childbirth and expanding painless childbirth. All interventions were divided into educational strategy and managerial strategy. The interventions can be implemented to change the behaviour of physicians and attitude of pregnant women in order to reduce caesarean section. In this regard, the authorities are recommended to make more efforts.
\end{abstract}

Keywords: pregnant women, caesarean section, childbirth

\section{Introduction}

Childbirth is one of the most sensitive and important services of the health system in all societies and caesarean section is considered as one of the main concerns in this regard (1). Caesarean section refers to the removal of the placenta, embryo and membranes by cutting the abdominal wall and uterus (2). Although caesarean section has played a significant role in reducing the mortality and morbidity of high- risk natural childbirth in the last century, its high level is a challenging issue during the recent decades (3).

Caesarean section, without medical indication, creates a lot of troubles on families, medical personnel and medical equipment which can lead to side effects for pregnant women and foetus compared to natural childbirth including the problems related to anaesthesia, post-operative infection, high haemorrhage and thromboembolism (4-6). In addition, caesarean 
section can have some side effects for infant such as respiratory problems, hospitalisation at the NICU, the possibility of infection, asthma in childhood and reduced breastfeeding (7). Some studies indicated that the reduction of caesarean section affects the maternal and neonatal mortality (8-10).

Further, caesarean section leads to more costs than natural childbirth $(11,12)$. Douangvichit et al., in their study, at two public hospitals in Latos indicated that the average cost for caesarean section and natural childbirth is 270 and 59 dollars, respectively (13). Based on the World Health Organization (WHO) statistics in different countries, the expected caesarean section should be $10 \%-15 \%$ and it is announced that there is no reason to increase the caesarean section (14). Based on the latest reports from 150 countries in the world, $18.6 \%$ of childbirths in the world are performed by caesarean section which is from $6.6 \%$ in developed countries and $27.2 \%$ in less developed countries (15).

Considering its effects on maternal health and reducing the cost of treatment and the economy of the family and country, most governments adopted some measures to reduce this problem. Such policies and interventions include the changes in the steps of natural childbirth leading to some caesarean section decisions and free natural childbirth (16). Since no study has been conducted on the interventions and policies implemented in different countries to reduce caesarean section, this study aimed to review the policies adopted in this area and evaluate their effectiveness.

\section{Methods}

\section{Study Design}

This systematic review study was conducted according to the Preferred Reporting Items for Systematic Reviews and Meta-Analyses (PRISMA) guidelines (17). The present systematic review study aimed to examine the interventions to reduce caesarean section in the world during 2000-2018 through searching in Embase, PubMed, Scopus, Web of Science, Science Direct, Magiran, SID and grey literature.

\section{Search Strategy}

The key words and search strategy were as follows: i) caesarean or caesarean section or repeat caesarean section or pregnancy or pregnant woman or parturition or birth or labour; and

ii) intervention or policy or plan or programme or, strategy or strategic planning; and

iii) decrease or change or impact or health impact assessment.

\section{Eligibility Criteria}

The inclusion criteria for selecting the studies related to the field of research included: i) the studies published during 2000-2018 ii) the studies in English or Persian and iii) the studies referring to at least one aspect of policy interventions to reduce caesarean section. The exclusion criteria included the letter to the editor, commentaries and the articles presented at the conferences.

\section{Quality Assessment}

After extracting the articles from the abovementioned databases, they were evaluated using the descriptive-analytical, Strengthening the Reporting of Observational Studies in Epidemiology (STROBE) checklist and the articles without any good quality of reporting were excluded.

\section{Results}

A total of 5,559 articles were reviewed, among which 2,778 articles were repetitive. A total of 2,781 articles were screened of which 2,680 articles were eliminated in the review of the title and abstract. Then, the full text of 101 articles was studied among which 82 articles were excluded (62 articles due to inadequate results and 20 articles due to poor quality). Finally, 19 articles were included. The abovementioned items are listed in Figure 1.

\section{Data Extraction}

After reviewing the quality of articles, 19 articles were eventually reviewed by three individuals. The information obtained from the articles were included in Word software and in the table containing the author's name, year of publication, sample size, analysis method, type of intervention, method of investigation, the most important results and conclusion. 
Review Article | Interventions in reducing caesarean section

\section{Summary of Reviewed Articles}

A total of 19 articles conducted in different parts of the world during the year 2000-2018 were evaluated after screening in terms of quality and relevance. The processes of reviewing the studies are presented in Figure 1.

Regarding to the target population of the studies, 11 studies were conducted in hospital, 6 studies in health centres and 2 studies in other places. Most studies were conducted after the year 2010 (76\%). Asia (67\%) allocated the most studies. In terms of research methodology, most of the studies were interventional $(67 \%)$ and $21 \%$ were retrospective studies related to the evaluation programmes, which were already conducted while $12 \%$ of the studies were combined. The context of other studies is shown in Table 1.

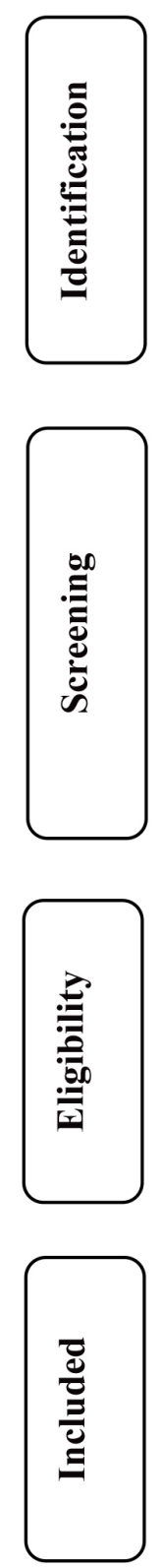

Articles identified through electronic database search: $\mathbf{5 , 5 5 9}$

(Embase: 101; PubMed: 1,305; Scopus: 958; Web of Science: 525;

Science Direct: 1,712; Magiran: 305; SID: 653)

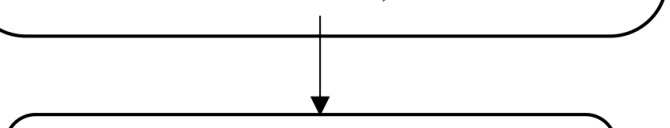

Articles after removing duplicated records: $\mathbf{2 , 7 7 8}$

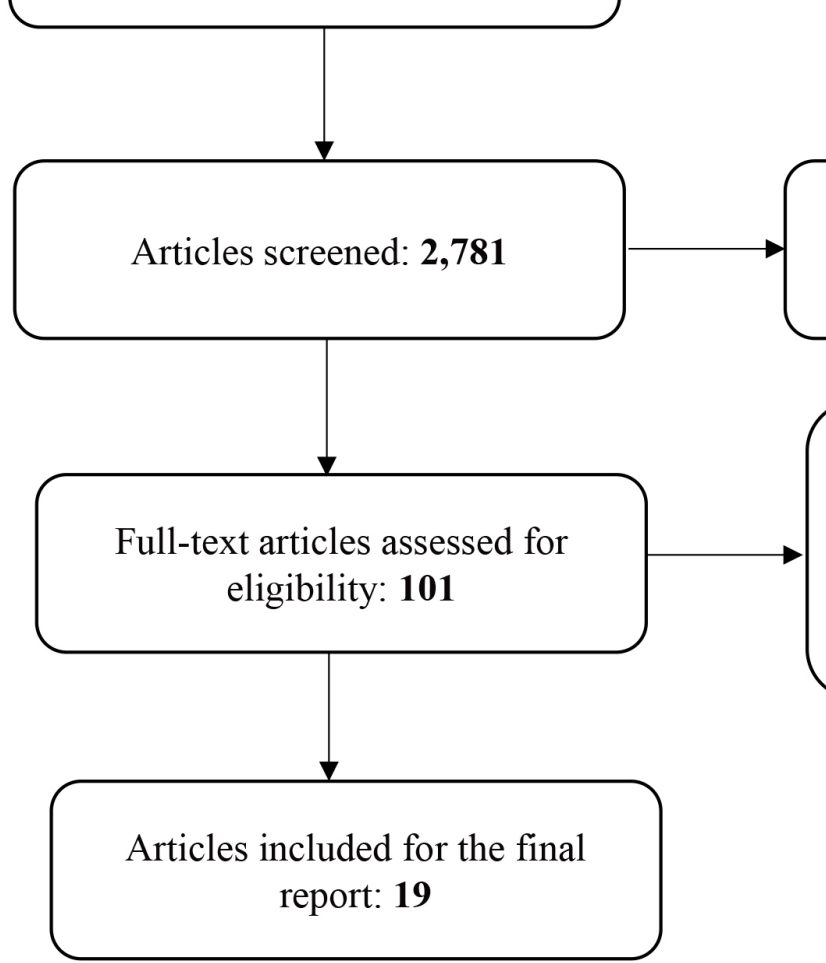

Records excluded in tittle and abstract screened: $\mathbf{2 , 6 8 0}$

Full-text articles excluded, with reasons: 82

Inadequate or inappropriate results: 62

Poor quality reporting: 20

Figure 1. Review selection process and results based on the PRISMA guidelines 
Table 1. Countries that studied

\begin{tabular}{lc} 
Country & Number of studies \\
Iran & 10 studies \\
China & 2 studies \\
US & 2 studies \\
France & 1 study \\
India & 1 study \\
Pakistan & 1 study \\
Taiwan & 1 study \\
Argentina, Brazil, Cuba, & 1 study \\
Guatemala, Mexico & \\
\hline
\end{tabular}

The strategies obtained from the results of the studies were divided into managerial and educational strategies.

\section{Educational Strategy}

This strategy is a collection of methods and tools for raising the awareness of pregnant women, their families and specialists. Based on the current studies, this strategy has the following sub-categories:

i) Training the pregnant women and their families ii) Training the specialists

iii) Applying an experienced person to accompany and train pregnant women in the hospital

iv) Training the benefits of natural childbirth and side effects of caesarean section to the husbands of pregnant women

\section{Managerial Strategy}

i) Performing natural childbirth as free

ii) Encouraging natural childbirth with the spread of painless childbirth

iii) Studying and making decision for caesarean section by experienced physicians in the hospital

iv) Having confidential correspondence with surgeons for conducting caesarean section in the hospital and the surgeon himself

v) Using the Six Sigma method

vi) Changing the guidelines and defining the various stages of childbirth 
Review Article | Interventions in reducing caesarean section

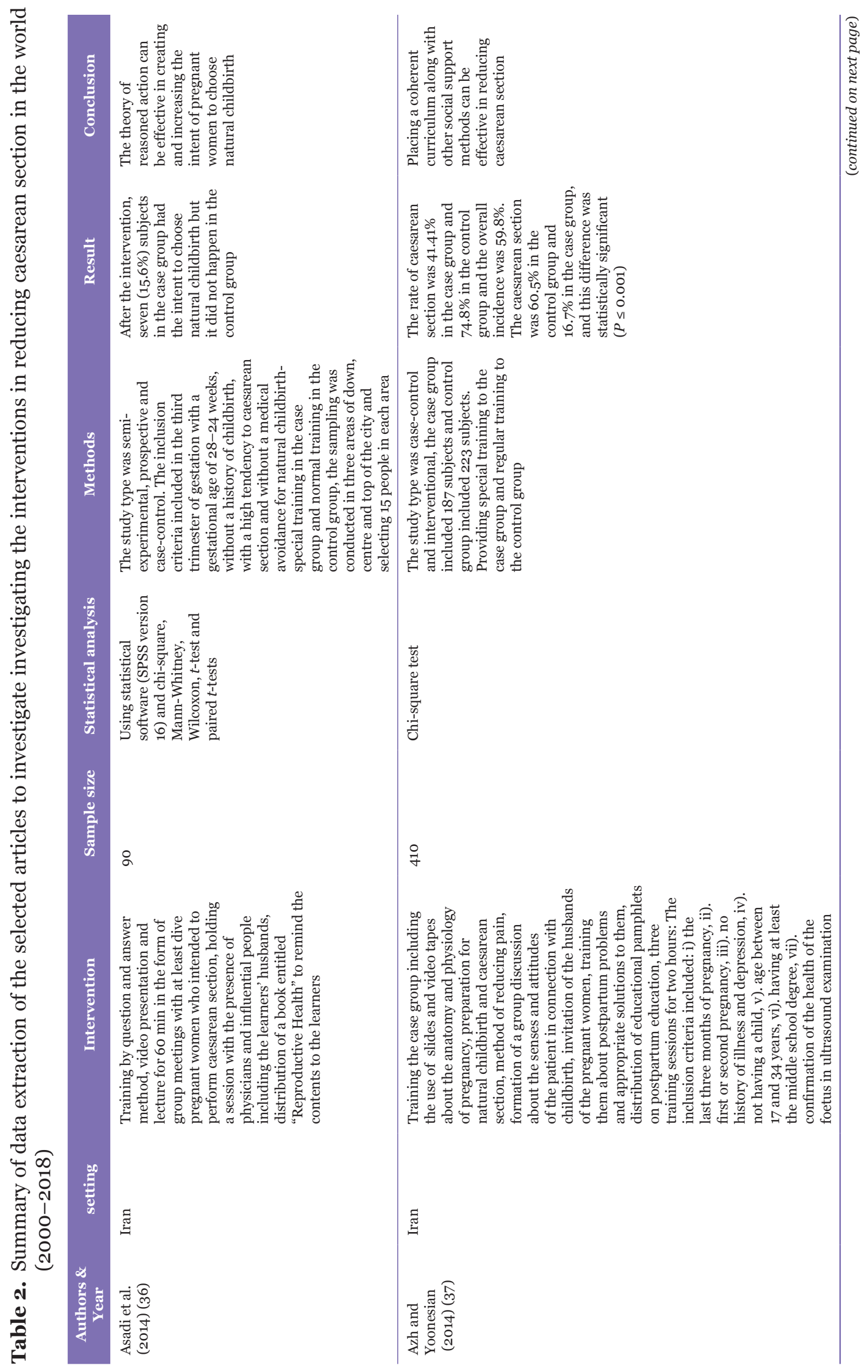




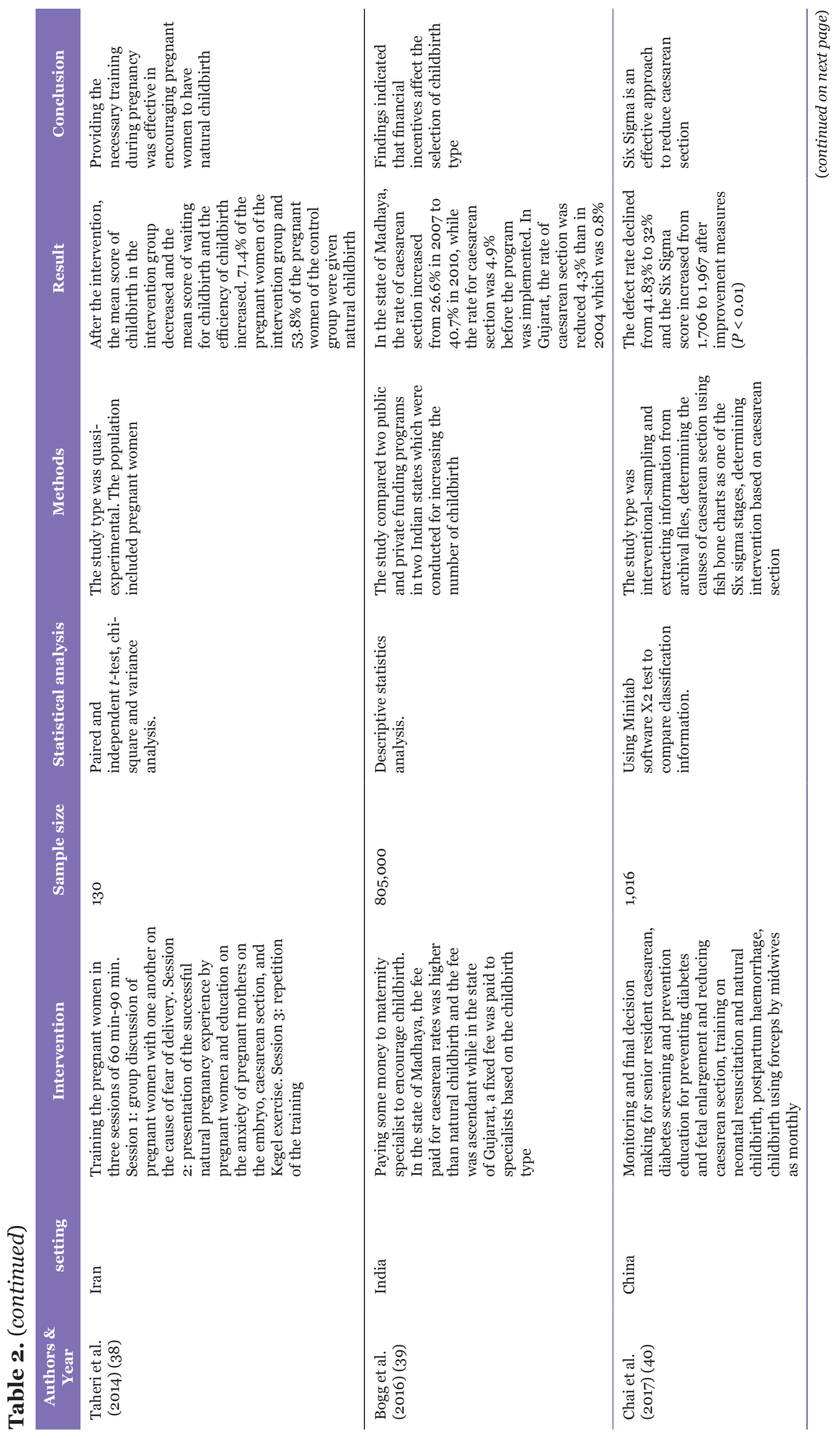


Review Article | Interventions in reducing caesarean section

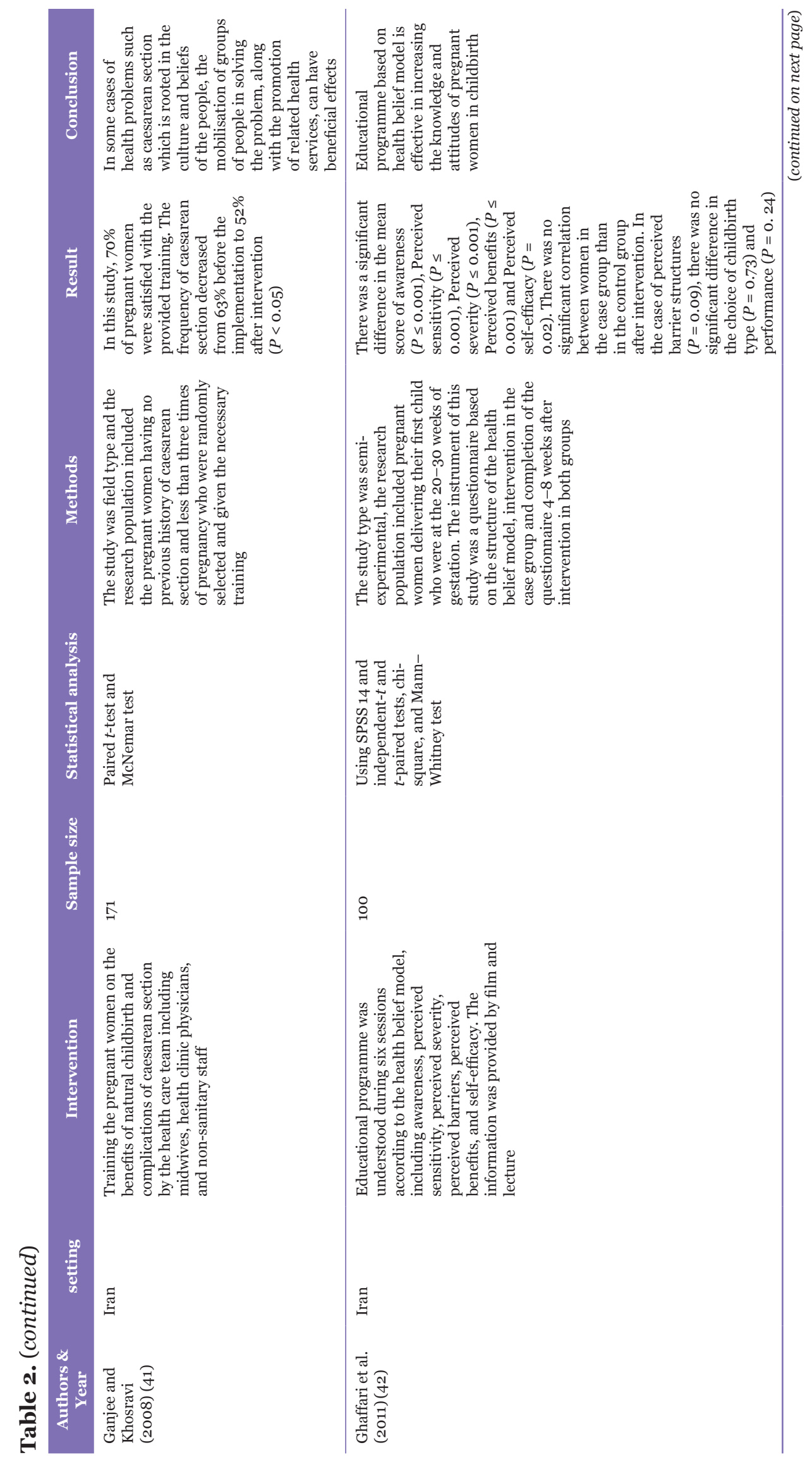




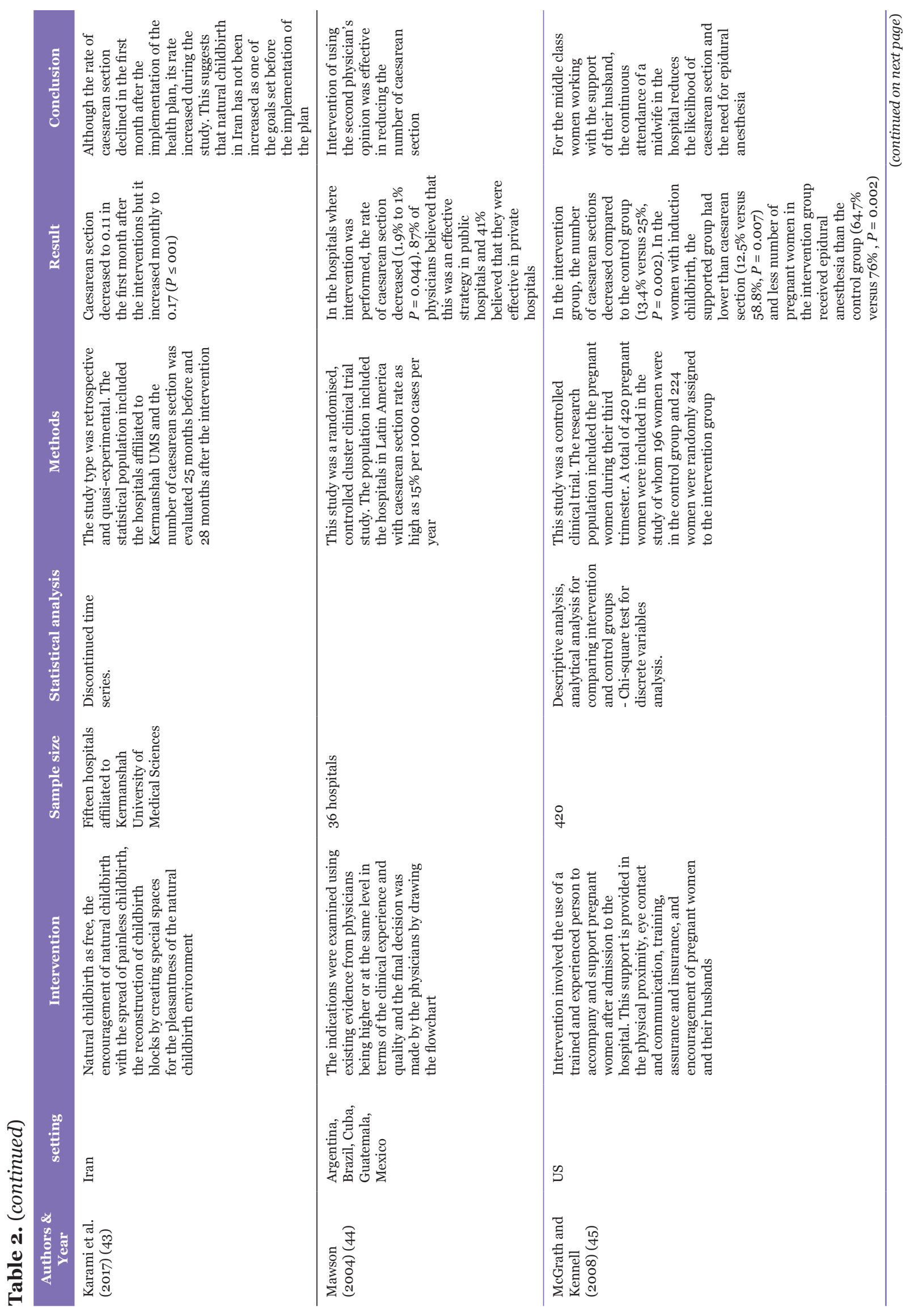


Review Article | Interventions in reducing caesarean section

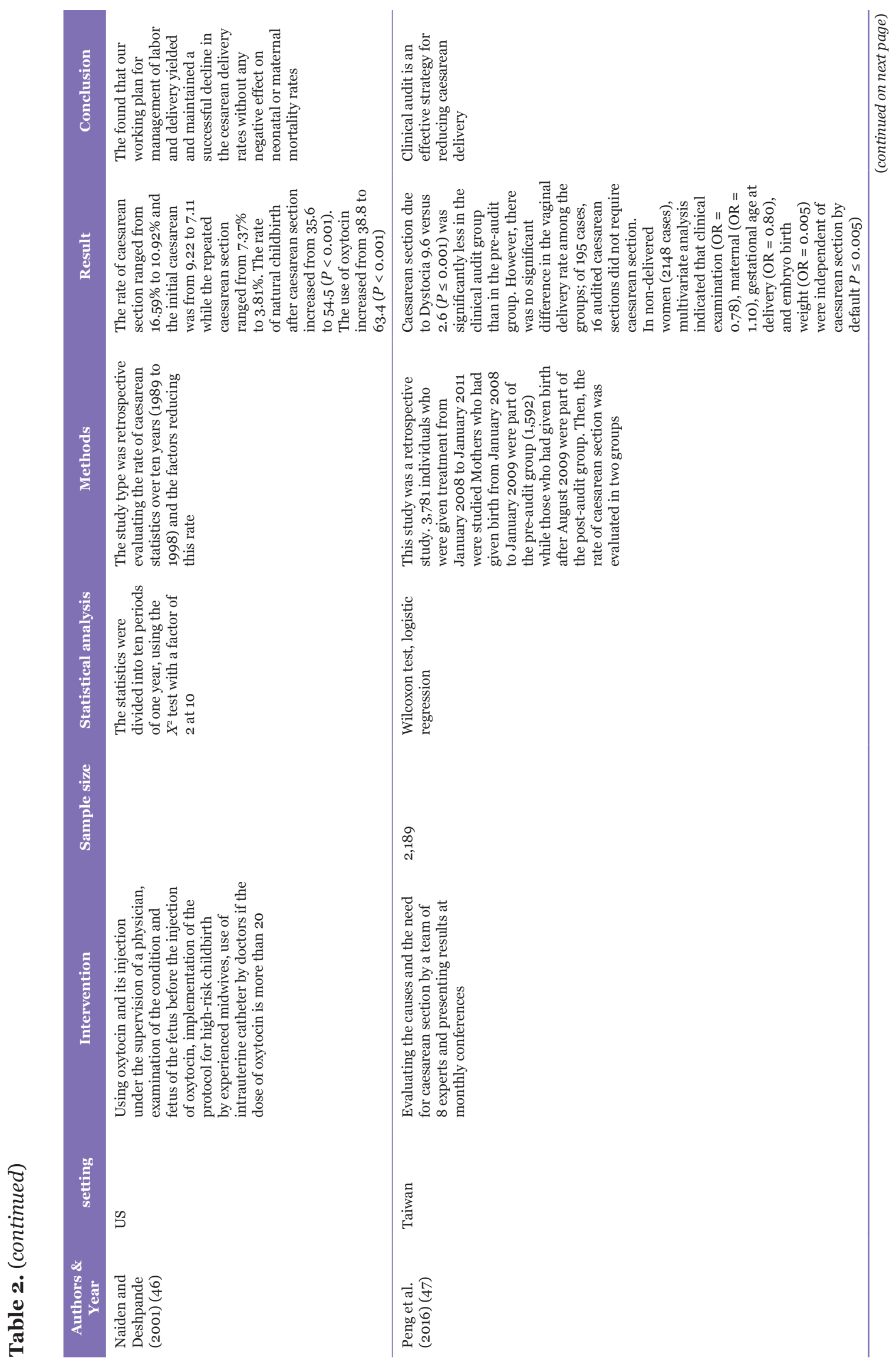




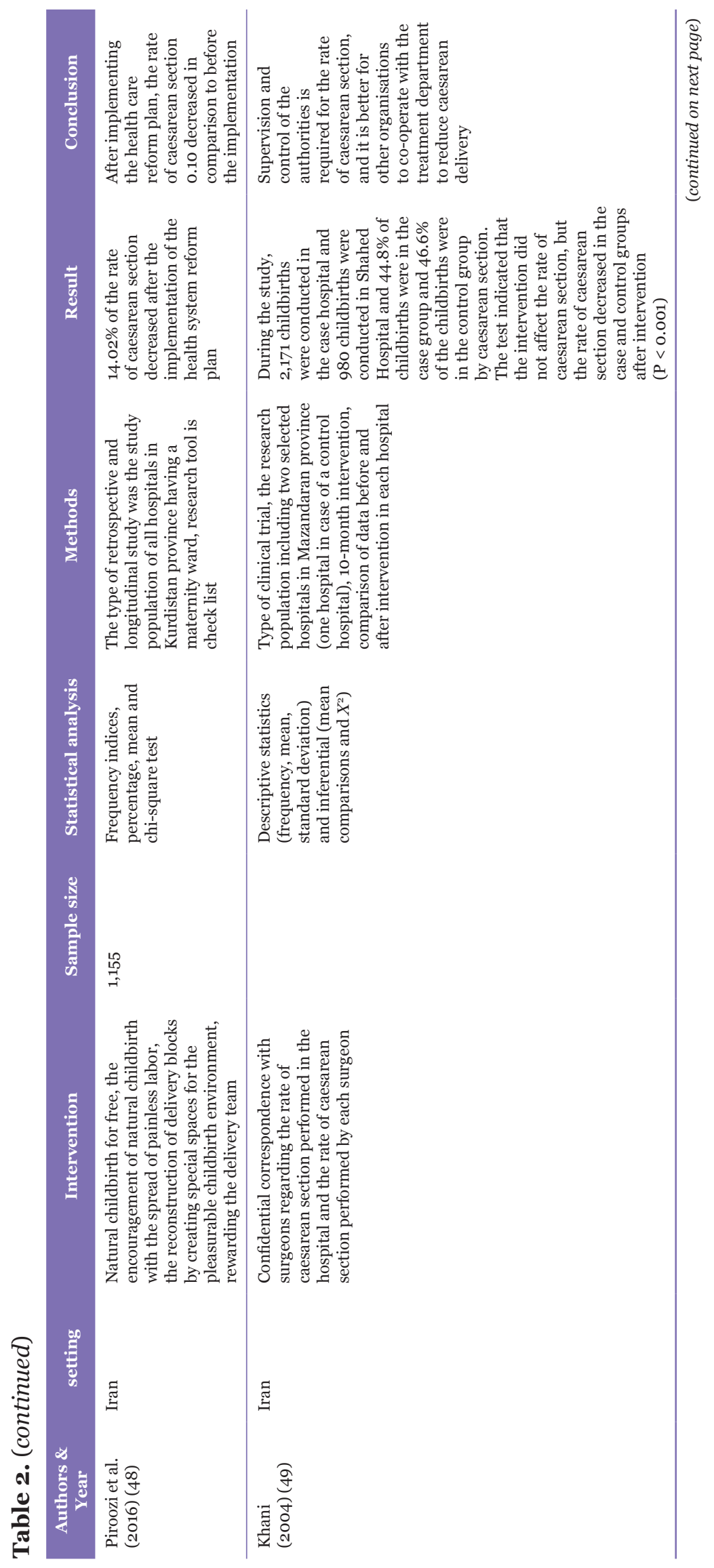


Review Article | Interventions in reducing caesarean section

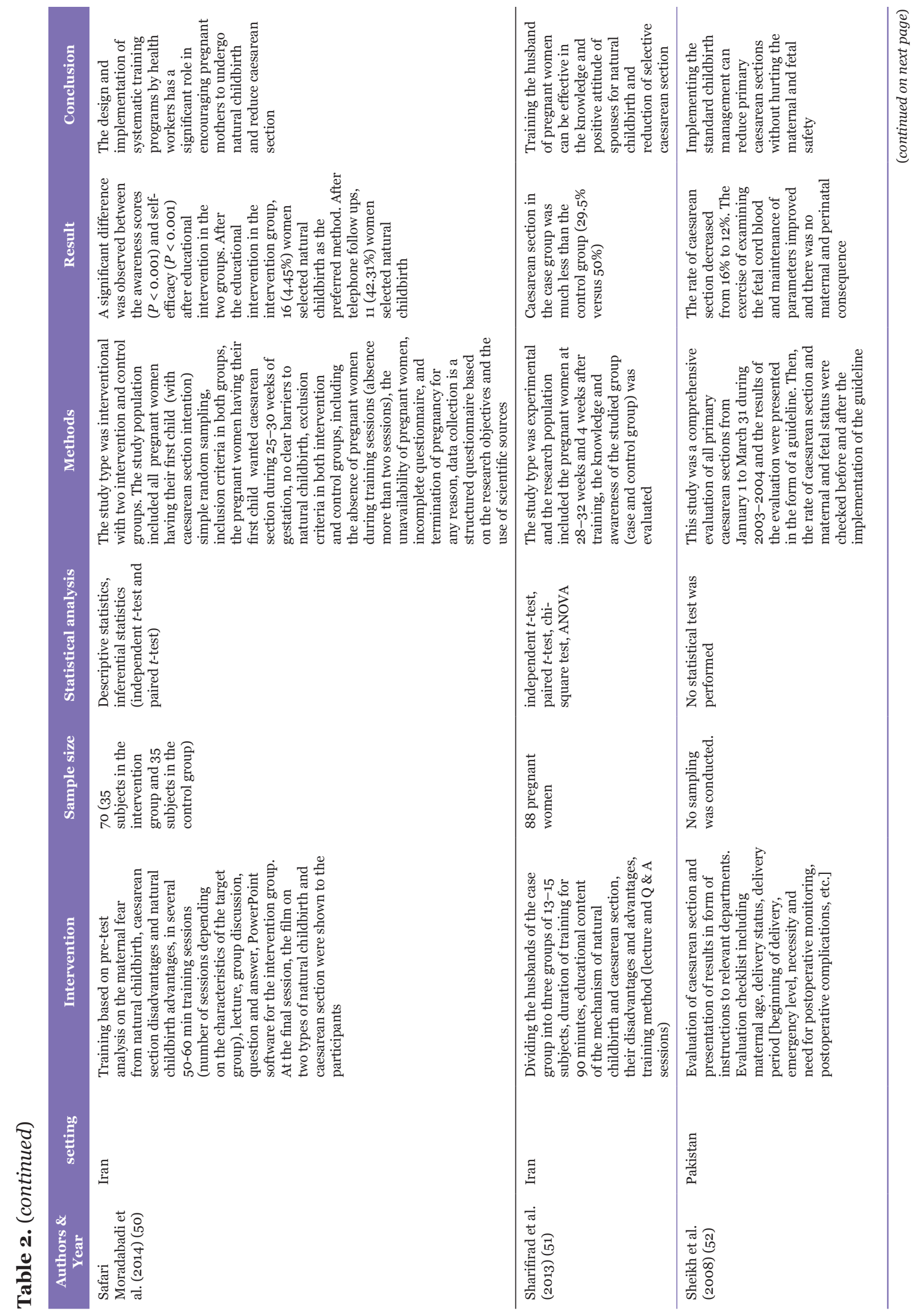




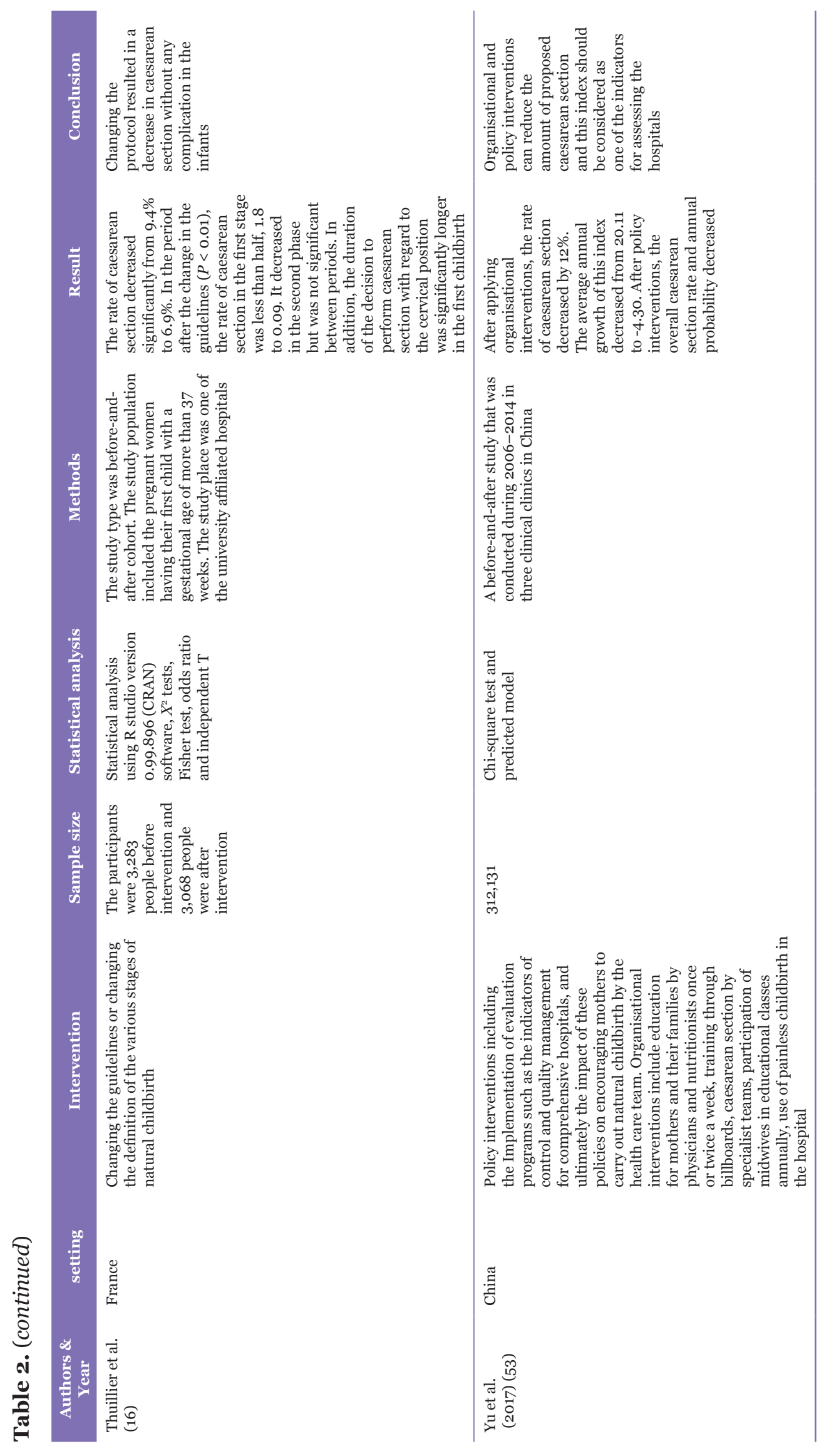


Review Article | Interventions in reducing caesarean section

\section{Discussion}

The results of this study indicated that education is effective in reducing caesarean section. The results of this study are consistent with studies of Spinelli et al. (18) and Ferguson et al. (19) but inconsistent with the studies of Artieta-Pinedo et al. (20) and, Bostani and Rafat (21).

It seems that the differences in the studied population such as the level of education, attitude of people and the readiness of people to attend educational classes are not affected by the difference between the results obtained from these studies. Other factors affecting the outcomes of education includes the skills and experiences of the trainer, the extent he addressed all the aspects of the subject and whether he was able to transfer it to the learners. In addition, the number of learners and their interest in learning, the time and number of hours spent in the classroom are influential in this regard.

The findings of this study indicated that training the husbands is effective in reducing caesarean section. Noghaee and Hadizadeh indicated that implementing the educational programme and raising the awareness of men can be effective in social protection of women (22).

Considering that men are one of the important pillars of reproductive health services, their role as the closest person to their spouse was confirmed in supporting the women and running family planning programmes. Thus, it is suggested that men should be trained and justified to transfer the learned knowledge to their spouses, which results in increasing women's awareness and reducing caesarean section.

Sharghi et al. indicated a significant relationship between the opinion of the spouse and the desire to choose caesarean section (23). In another study, Faraji Darkhaneh and Farjad Bastani indicated that $64 \%$ of women considered the role of the spouse in choosing the method of childbirth (24).

The results of this study indicated that using a midwife is effective in reducing caesarean section. As a result, the presence of a midwife after the childbirth, facilitates the pregnant women readiness for infants and postpartum affairs. Furthermore, the results of Kozhimannil et al.'s study indicated that the presence of a midwife is effective in reducing caesarean section (25).

Considering the role of midwife in the care of pregnant women before, during and after childbirth, as well as preventing the complications and risks of pregnancy by this group of people, it is recommended to pay more attention to this issue and provide special conditions and facilities for using pregnant women including the easy and inexpensive access.

The results of this study indicated that the evaluation and indication of caesarean section as well as using the feedback to specialists had a slight effect on the rate of caesarean section. The results of Khunpradit et al.'s review study (26) are in line with the results of this study. The results of Tavarez et al.'s study indicated that the feedback of performance to pediatric emergency physicians over a three-month period is ineffective in the management of patients with diarrhea and vomiting (27). In another study, $\mathrm{Tu}$ et al. confirmed that the announcement of hospital indicators is ineffective in improving the indices (28). The results of these studies were inconsistent with those in the present study.

Based on the results of a meta-analysis study, feedback and evaluation were effective at a rate of $13 \%$ in reducing the caesarean section (29). In addition, the results of some studies are not in line with those in the present study (3033).

It seems that the underlying characteristics of the environment where feedback is performed including the amount of personnel's attention and belief in feedback is not ineffective in the obtained results. Sargeant et al. indicated that the reaction and perception of physicians to multi-stage feedbacks can affect their performance (34). However, the characteristics of service providers, the way of providing feedback and the extent of real feedback to personnel may not be ineffective in their feedback.

Physician-patient relationship culture in Iran indicates that medical team can play an important role in controlling or stimulating caesarean statistics. It is suggested that physicians should always be given the necessary feedback in this regard. Obviously, this control has a moral value physically and economically. The findings of this study stated the level of tariffs on caesarean section reduction. The results of the study by Fabri and Murta confirmed this finding (35). 
Interventions in the developed countries (change in guidelines) were more systematic in this study and involved a wide range of women, leading to the better process of natural childbirth and caesarean section reduction. However, the interventions in developing countries including Iran had a personal dimension including only a few people who are learners. The lack of transparency in the research method in a limited number of studies was one of the limitations encountered by the researchers in this study. It is suggested that future studies should include the interventions, which are more systematic and functional.

\section{Conclusion}

Finally, the researcher believed that modifying the referral system for childbirth is considered as the most important method for reducing the caesarean section. All the patients should first be examined by midwife and referred to a specialist in case of necessity and the need for the indications of caesarean section. Further, training the pregnant women and their husbands, performing natural childbirth as free, studying and making decision for caesarean section by experienced physicians in the hospital, encouraging natural childbirth with the spread of painless childbirth are considered as effective.

\section{Acknowledgements}

The researchers would like to thank the Clinical Research Development Unit of the Educational Treatment Center of Imam Reza (PBUH).

\section{Conflict of Interest}

None.

\section{Funds}

None.

\section{Authors' Contributions}

Conception and design: FM

Analysis and interpretation of the data: FM, AS

Drafting of the article: FM, MH

Critical revision of the article for important intellectual content: $\mathrm{MH}$

Final approval of the article: FM, AS, MH

Provision of study materials or patients: SRS

Statistical expertise: AS

Obtaining of funding: FM

Administrative, technical, or logistic support: FM, MH, AA, AS, SRS

Collection and assembly of data: FM, AA, AS, MH, SRS

\section{Correspondence}

\section{Dr Ali Soroush}

Life Style Modification Research Center, Imam Reza Hospital,

Kermanshah University of Medical Sciences, Kermanshah, Iran.

Tel: +989188309157

Fax: +o83 34276301

E-mail: ali.soroush.mhr@gmail.com

\section{References}

1. Shakeri M, Mazloumzade S, Mohamaian F. Factors affecting the rate of cesarean section in Zanjan maternity hospitals in 2008. ZUMS J. 2012;20(80):98-104.

2. Cunningham F, Leveno K, Bloom S, Spong CY, Dashe J. Williams Obstetrics, 24th ed. USA: McGraw-Hill; 2014.

3. Besharati F, Hazavehei S, Moeini B, Moghimbeigi A. Effect of educational interventions based on theory of planned behavior (TPB) in selecting delivery mode among pregnant women referred to Rasht health centers. J ZUMS Health Serv. 2011;19(77):95-106.

4. Souza JP, Gülmezoglu A, Lumbiganon P, Laopaiboon M, Carroli G, Fawole B, et al. Caesarean section without medical indications is associated with an increased risk of adverse short-term maternal outcomes: the 2004-2008 WHO Global Survey on Maternal and Perinatal Health. BMC Med. 2010;8(1):71. https://doi. org/10.1186/1741-7015-8-71 
Review Article | Interventions in reducing caesarean section

5. Villar J, Carroli G, Zavaleta N, Donner A, Wojdyla D, Faundes A, et al. Maternal and neonatal individual risks and benefits associated with caesarean delivery: multicentre prospective study. BMJ. 2007;335(7628):1025. https://doi. org/10.1136/bmj.39363.706956

6. Lumbiganon P, Laopaiboon M, Gülmezoglu AM, Souza JP, Taneepanichskul S, Ruyan $\mathrm{P}$, et al. Method of delivery and pregnancy outcomes in Asia: the WHO global survey on maternal and perinatal health 2007-2008. Lancet. 2010;375(9713):490-499. https://doi. org/10.1016/So140-6736(o9)61870-5

7. Smith H, Peterson N, Lagrew D, Main E. Toolkit to support vaginal birth and reduce primary cesareans: a quality improvement toolkit. California Maternal Quality Care Collaborative; 2016.

8. Althabe F, Sosa C, Belizán JM, Gibbons L, Jacquerioz F, Bergel E. Cesarean section rates and maternal and neonatal mortality in low-, mediumand high-income countries: an ecological study. Birth. 2006;33(4):270-277. https://doi. org/10.1111/j.1523-536X.2006.00118.x

9. Dumont A, De Bernis L, Bouvier-olle M-H, Bréart G, Group MS. Caesarean section rate for maternal indication in sub-Saharan Africa: a systematic review. Lancet. 2001;358(9290):1328-1333. https://doi.org/10.1016/So140-6736(01)06414-5

10. Betran AP, Torloni MR, Zhang J, Ye J, Mikolajczyk R, Deneux-Tharaux C, et al. What is the optimal rate of caesarean section at population level? A systematic review of ecologic studies. Reprod Health. 2015;12(1):57. https:// doi.org/10.1186/s12978-015-0043-6

11. Spong CY, Berghella V, Wenstrom KD, Mercer BM, Saade GR. Preventing the first cesarean delivery: summary of a joint Eunice Kennedy Shriver national institute of child health and human development, society for maternal-fetal medicine, and American college of obstetricians and gynecologists workshop. Obstet and Gynecol. 2012;120(5):1181-1193.

12. Caughey AB, Cahill AG, Guise J-M, Rouse DJ, Obstetricians ACo, Gynecologists. Safe prevention of the primary cesarean delivery. Am J Obstet Gynecol. 2014;210(3):179-193. https://doi. org/10.1016/j.ajog.2014.01.026
13. Douangvichit D, Liabsuetrakul T, McNeil E. Health care expenditure for hospital-based delivery care in Lao PDR. BMC Res Notes. 2012;5(1):30. https://doi.org/10.1186/17560500-5-30

14. O'dwyer V, Hogan JL, Farah N, Kennelly MM, Fitzpatrick C, Turner MJ. Maternal mortality and the rising cesarean rate. Int $J$ Gynecol Obstet. 2012;116(2):162-164. https://doi.org/10.1016/j. ijgo.2011.09.024

15. Betrán AP, Ye J, Moller A-B, Zhang J, Gülmezoglu AM, Torloni MR. The increasing trend in caesarean section rates: global, regional and national estimates: 1990-2014. PloS One. 2016;11(2):e0148343. https://doi.org/10.1371/ journal.pone.0148343

16. Thuillier C, Roy S, Peyronnet V, Quibel T, Nlandu A, Rozenberg P. Impact of recommended changes in labor management for prevention of the primary cesarean delivery. Am J Obstet Gynecol. 2018;218(3):341. https://doi.org/10.1016/j. ajog.2017.12.228

17. Hutton B, Catala-Lopez F, Moher D. The PRISMA statement extension for systematic reviews incorporating network meta-analysis: PRISMANMA. Med Clin (Barc). 2016;147(6):262-266. https://doi.org/10.1016/j.medcli.2016.02.025

18. Spinelli A, Baglio G, Donati S, Grandolfo M, Osborn J. Do antenatal classes benefit the mother and her baby? J Maternal-Fetal Neonatal Med. 2003;13(2):94-101. https://doi.org/10.1080/ jmf.13.2.94.101

19. Ferguson S, Davis D, Browne J. Does antenatal education affect labour and birth? A structured review of the literature. Women Birth. 2013;26(1):e5-e8. https://doi.org/10.1016/j. wombi.2012.09.003

20. Artieta-Pinedo I, Paz-Pascual C, Grandes G, Remiro-Fernandezdegamboa G, OdriozolaHermosilla I, Bacigalupe A, et al. The benefits of antenatal education for the childbirth process in Spain. Nurs Res. 2010;59(3):194-202. https:// doi.org/10.1097/NNR.obo13e3181dbbb4e

21. Bostani Khalesi Z, Rafat F. Relationship between adequacy of prenatal care utilization. $J$ Holistic Nurs Midwifery. 2015;25(2):8-15. 
22. Noghaee A, Hadizadeh F. Effect of menopause training on spouses on social support perceived by postmenopausal women. Quarterly $J$ Monitor. 2004;8(4):343-348.

23. Sharghi A, Kamran A, Sharifirad G. Assessing the factors influencing delivery method selection in primiparous pregnant women referred to health centers in Ardabil, 2010. Bimonthly J HUMS. 2011;15(3):234-242.

24. Faraji Darkhaneh RZ, Farjad Bastani F. Knowledge and attitudes of pregnant women towards birth methods. $J$ GUMS. 2011;12(46):69-75.

25. Kozhimannil KB, Hardeman RR, Attanasio LB, Blauer-Peterson C, O'brien M. Doula care, birth outcomes, and costs among Medicaid beneficiaries. Am $J$ Public Health. 2013;103(4):e113-e121. https://doi.org/10.2105/ AJPH.2012.301201

26. Khunpradit S, Tavender E, Lumbiganon $\mathrm{P}$, Laopaiboon M, Wasiak J, Gruen RL. Nonclinical interventions for reducing unnecessary caesarean section. Cochrane Database Syst Rev. 2011;6:CDoo5528. https://doi. org/10.1002/14651858.CDoo5528.pub2

27. Tavarez MM, Ayers B, Jeong JH, Coombs CM, Thompson A, Hickey RW. Practice variation and effects of e-mail-only performance feedback on resource use in the emergency department. Academic Emerg Med. 2017;24(8):948-956. https://doi.org/10.1111/acem.13211

28. Tu JV, Donovan LR, Lee DS, Wang JT, Austin PC, Alter DA, et al. Effectiveness of public report cards for improving the quality of cardiac care: the EFFECT study: a randomized trial. JAMA. 2009;302(21):2330-2337. https://doi. org/10.1001/jama.2009.1731

29. Chaillet N, Dumont A. Evidence-based strategies for reducing cesarean section rates: a metaanalysis. Birth. 2007;34(1):53-64. https://doi. org/10.1111/j.1523-536X.2006.00146.x

30. Salinas H, Carmona S, Albornoz J, Veloz P, Terra $\mathrm{R}$, Marchant R, et al. Se puede reducir el índice de cesárea? Experiencia del Hospital Clínico de la Universidad de Chile. Revista Chilena de Obstetricia y Ginecología. 2004;69(1):8-13. http://dx.doi.org/10.4067/So717-752620040001 00003
31. Ivers $\mathrm{N}$, Jamtvedt G, Flottorp S, Young JM, Odgaard-Jensen J, French SD, et al. Audit and feedback: effects on professional practice and healthcare outcomes. Cochrane Database Syst Rev. 2012;6:CDoo0259. https://doi. org/10.1002/14651858.CDooo259.pub3

32. Price-Haywood EG, Harden-Barrios J, Cooper LA. Comparative effectiveness of audit-feedback versus additional physician communication training to improve cancer screening for patients with limited health literacy. $J$ General Internal Med. 2014;29(8):1113-1121. https://doi. org/10.1007/s11606-014-2782-4

33. Mostofian F, Ruban C, Simunovic N, Bhandari M. Changing physician behavior: what works. $\mathrm{Am} \mathrm{J}$ Manag Care. 2015;21(1):75-84.

34. Sargeant J, Mann K, Ferrier S. Exploring family physicians' reactions to multisource feedback: perceptions of credibility and usefulness. Med Edu. 2005;39(5):497-504. https://doi. org/10.1111/j.1365-2929.2005.02124.x

35. Fabri R, Murta E. Socioeconomic factors and cesarean section rates. Int $J$ Gynecol Obstet. 2002;76(1):87-88. https://doi.org/10.1016/ Soo20-7292(01)00544-6

36. 36. Asadi ZS, Solhi M, Taghdisi MH, Moghadam Hoseini V, Javan R, Hashemian M. The effect of educational intervention based on Theory of Reasoned Action (TRA) on selected delivery method, for selective cesarean section in pregnant women. The Iranian Journal of Obstetrics, Gynecology and Infertility. 2014;17(109):1-8.

37. Azh NS, Yoonesian M. The effect of pregnancy classes on cesarean section. Journal Qazvin University Medical Science. 2014;14(4):71-76.

38. Taheri Z, Mazaheri MA, Khorsandi M, Hassanzadeh A, Amiri M. Effect of educational intervention on self-efficacy for choosing delivery method among pregnant women in 2013. Int $J$ Prev Med. 2014;5(10):1247-1254.

39. Bogg L, Diwan V, Vora KS, DeCosta A. Impact of alternative maternal demand-side financial support programs in India on the caesarean section rates: indications of supplier-induced demand. Matern Child Health J. 2016;20(1):1115. https://doi.org/10.1007/s10995-015-1810-2 
Review Article | Interventions in reducing caesarean section

40. Chai ZY, Hu HM, Ren XL, Zeng BJ, Zheng LZ, Qi F. Applying Lean Six Sigma methodology to reduce cesarean section rate. $J$ Eval Clin Pract. 2017;23(3):562-566. https://doi.org/10.1111/ jep. 12671

41. Ganjee FR, Khosravi S. The effect of participatory intervention on reducing the frequency of unnecessary cesarean in Shahrekord. Special Demographics Res. 2008;14:8.

42. Ghaffari M, Sharifirad G, Akbari Z, Khorsandi M, Hassanzadeh A. Health belief model-based education \& reduction of cesarean among pregnant women: an interventional study. Health System Research. 2011;7(2):200-208.

43. Karami Matin B, Hajizadeh M, Najafi F, Homaie Rad E, Piroozi B, Rezaei S. The impact of health sector evolution plan on hospitalization and cesarean section rates in Iran: an interrupted time series analysis. Int $J$ Qual Health Care. 2017;30(1):75-79. https://doi.org/10.1093/ intqhe/mzx169

44. Mawson AR. A mandatory second opinion policy reduces caesarean section rates in hospitals in Latin America. Evidence-Based Healthcare and Public Health. 2004;8(6):392-395. https://doi. org/10.1016/j.ehbc.2004.09.025

45. McGrath SK, Kennell JH. A randomized controlled trial of continuous labor support for middle-class couples: Effect on cesarean delivery rates. Birth. 2008;35(2):92-97. https://doi. org/10.1111/j.1523-536X.2008.00221.X

46. Naiden J, Deshpande P. Using active management of labor and vaginal birth after previous cesarean delivery to lower cesarean delivery rates: a 10-year experience. American $J$ Obstet Gynecol. 2001;184(7):1535-1543. https://doi. org/10.1067/mob.2001.114865
47. Peng F-S, Lin $\mathrm{H}-\mathrm{M}$, Lin $\mathrm{H}-\mathrm{H}$, Tu F-C, Hsiao C-F, Hsiao S-M. Impact of clinical audits on cesarean section rate. Taiwan J Obstet Gynecol. 2016;55(4):530-533. https://doi.org/10.1016/j. tjog.2014.12.015

48. Piroozi B, Moradi G, Esmail Nasab N, Ghasri H, Farshadi S, Farhadifar F. Evaluating the effect of health sector evolution plan on cesarean rate and the average costs paid by mothers: a case study in Kurdistan province between 2013-2015. Journal of Hayat. 2016;22(3):245-254.

49. Khani SS. Can you reduce the amount of cesarean in Mazandaran province? Journal Mazandaran University Medical Science. 2004;4(45):44-50.

50. Safari Moradabadi A, Hassani L, Ghanbarnejad A. The effect of education on knowledge and preferred method of delivery in nulliparous women. Journal of Health \& Care. 2014;16(1):74-83.

51. Sharifirad G, Rezaeian M, Soltani R, Javaheri S, Mazaheri MA. A survey on the effects of husbands' education of pregnant women on knowledge, attitude, and reducing elective cesarean section. $J$ Edu Health Promot. 2013;2:50. https://doi. org/10.4103/2277-9531.119036

52. Sheikh L, Tehseen S, Gowani SA, Bhurgri H, Rizvi J, Kagazwala S. Reducing the rate of primary caesarean sections--an audit. Journal of the Pakistan Medical Association. 2008;58(8):444448.

53. Yu Y, Zhang X, Sun C, Zhou H, Zhang Q, Chen C. Reducing the rate of cesarean delivery on maternal request through institutional and policy interventions in Wenzhou, China. PloS One. 2017;12(11):e0186304 